Supporting Information to accompany

\title{
Imaging and Modelling the Optical Emission from CH Radicals in Microwave Activated C/H Plasmas
}

\author{
Edward J.D. Mahoney, ${ }^{1,2}$ Bruno J. Rodriguez, ${ }^{1,2}$ Sohail Mushtaq, ${ }^{1}$ Benjamin S. Truscott, ${ }^{1}$
} Michael N.R. Ashfold ${ }^{1 *}$ and Yuri A. Mankelevich ${ }^{3 *}$

${ }^{1}$ School of Chemistry, University of Bristol, Bristol, U.K. BS8 1TS

${ }^{2}$ Centre for Doctoral Training in Diamond Science and Technology, University of Warwick, Gibbet Hill Road, Coventry, U.K., CV4 7AL

${ }^{3}$ Skobeltsyn Institute of Nuclear Physics, Lomonosov Moscow State University, Leninskie gory, Moscow, 119991, Russia 


\section{Figure S1}

$I_{\mathrm{em}}\left(\mathrm{CH}^{*}, z\right)$ distributions measured at $P=$ (a) 0.7 and (b) $1.85 \mathrm{~kW}$ and all other parameters maintained at their base values, with the respective $z_{\mathrm{m}}$ values indicated. (c) $z$-dependent $R(\mathrm{~B} / \mathrm{A})$ and $R(\mathrm{C} / \mathrm{A})$ values derived from these data and from the $P=1.5 \mathrm{~kW}$ data shown in Figure 2(b).

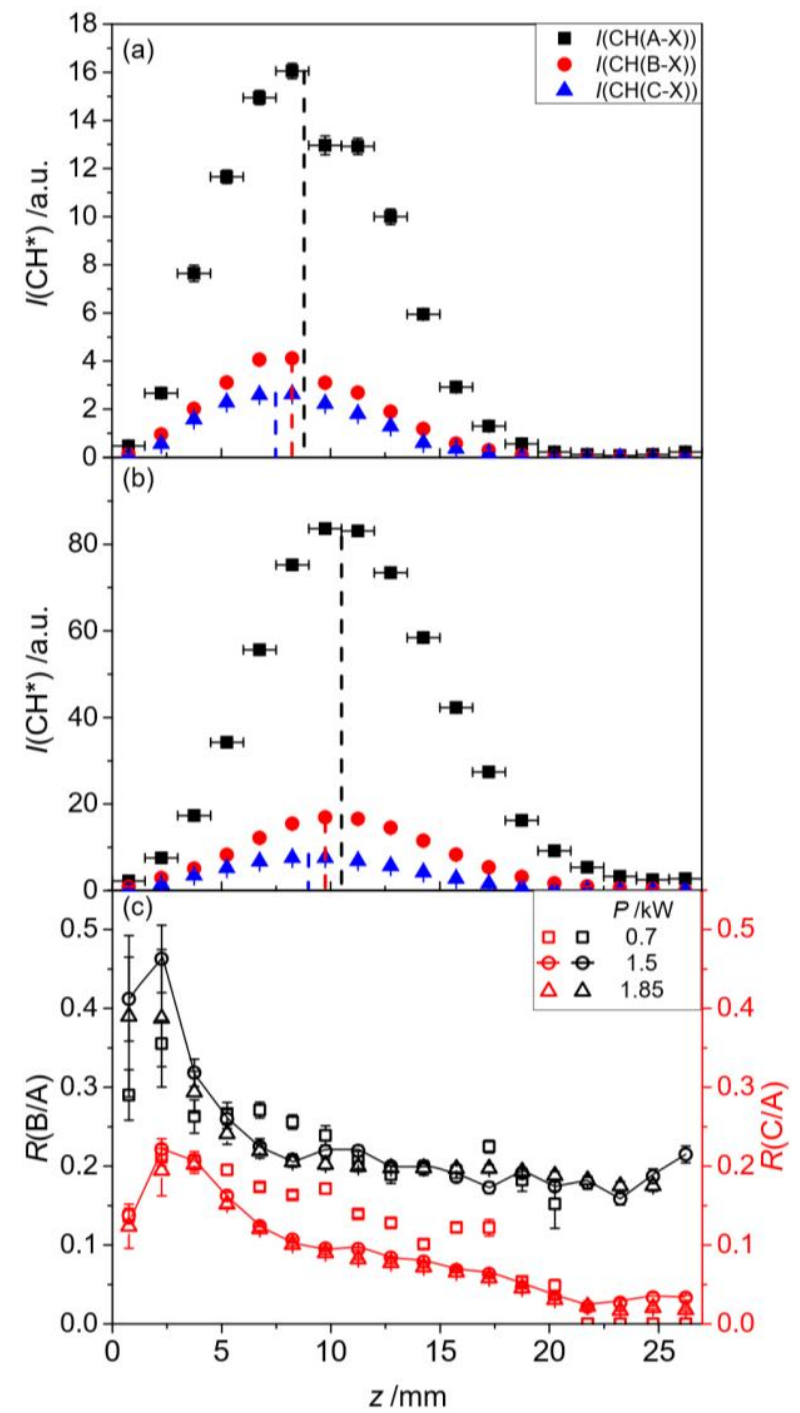




\section{Figure S2}

$I_{\mathrm{em}}\left(\mathrm{CH}^{*}, z\right)$ distributions measured for $d_{\text {sub }}=$ (a) $32 \mathrm{~mm}$ (i.e. base conditions), (b) $27 \mathrm{~mm}$ and (c) $17 \mathrm{~mm}$ using, respectively, $d_{\text {wire }}=0.01 ", 0.006 "$ and $0.004 "$ and with all other parameters held at their base values. The respective $z \mathrm{~m}$ values are indicated by the dashed vertical lines. (d) $z$-dependent $R(\mathrm{~B} / \mathrm{A})$ and $R(\mathrm{C} / \mathrm{A})$ values derived from these data.

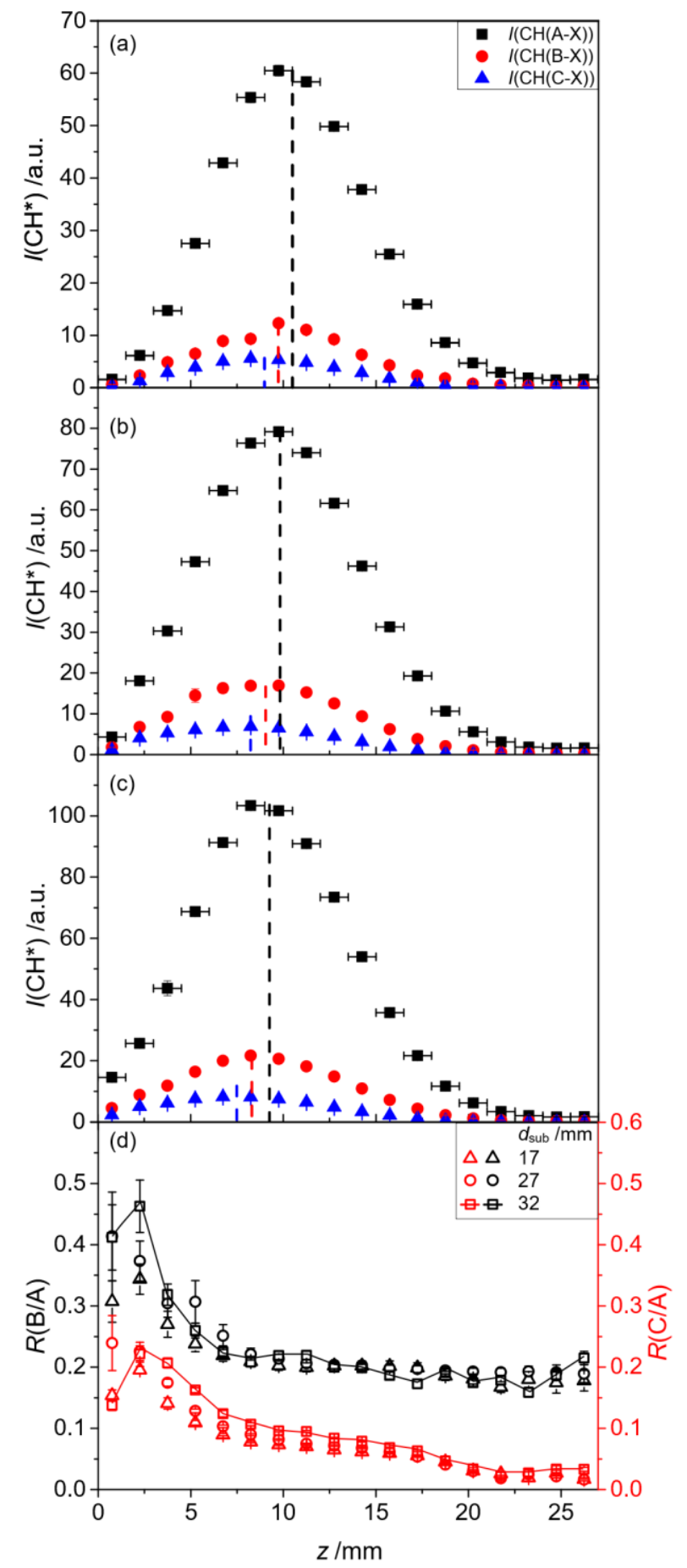




\section{Figure S3}

Temperature ( $T_{\text {gas }}$ ) dependent rate coefficients for the reactions: ${ }^{1} \mathrm{CH}_{2}+\mathrm{H} \rightarrow \mathrm{CH}(\mathrm{X})+\mathrm{H}_{2},{ }^{1} \mathrm{CH}_{2}+\mathrm{H}$ $\rightarrow \mathrm{CH}(\mathrm{A})+\mathrm{H}_{2}$ and ${ }^{1} \mathrm{CH}_{2}+\mathrm{H} \rightarrow \mathrm{CH}(\mathrm{C})+\mathrm{H}_{2}$.

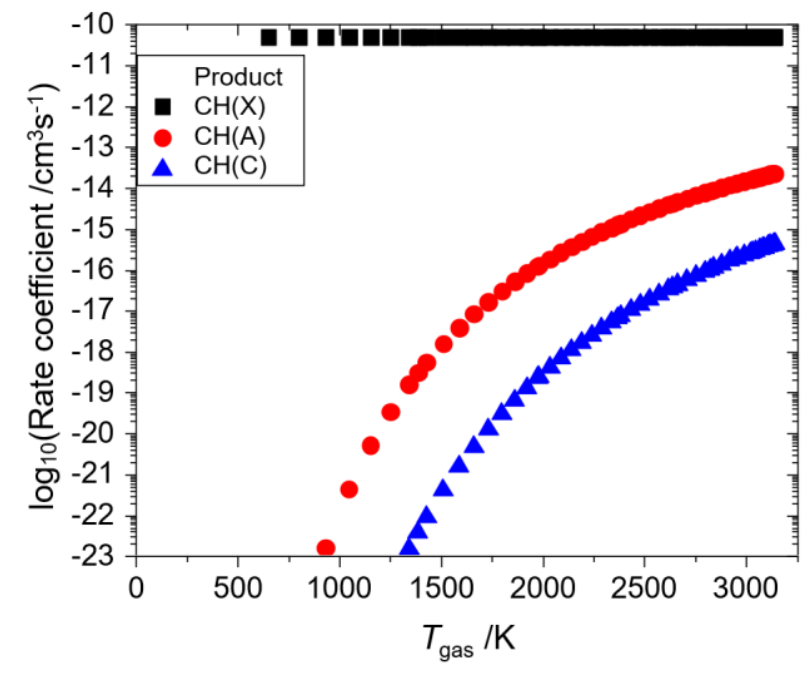




\section{Figure S4}

Plots comparing $I_{\mathrm{C}} / I_{\mathrm{A}}=A_{\mathrm{C}}\{\mathrm{CH}(\mathrm{C})\} /\left(A_{\mathrm{A}}\{\mathrm{CH}(\mathrm{A})\}\right.$ intensity ratios calculated with the inclusion of $\mathrm{CL}$ reaction (9b) (open symbols) and the experimental ratios $R(\mathrm{C} / \mathrm{A}) / R\left(\varepsilon_{\mathrm{det}}\right)$ ratios (filled symbols) for (a) $p$ $=75,150$ and 275 Torr (at $P=1.5 \mathrm{~kW}$ ) and (b) $P=0.7$ and $1.85 \mathrm{~kW}$ (at $p=150$ Torr).

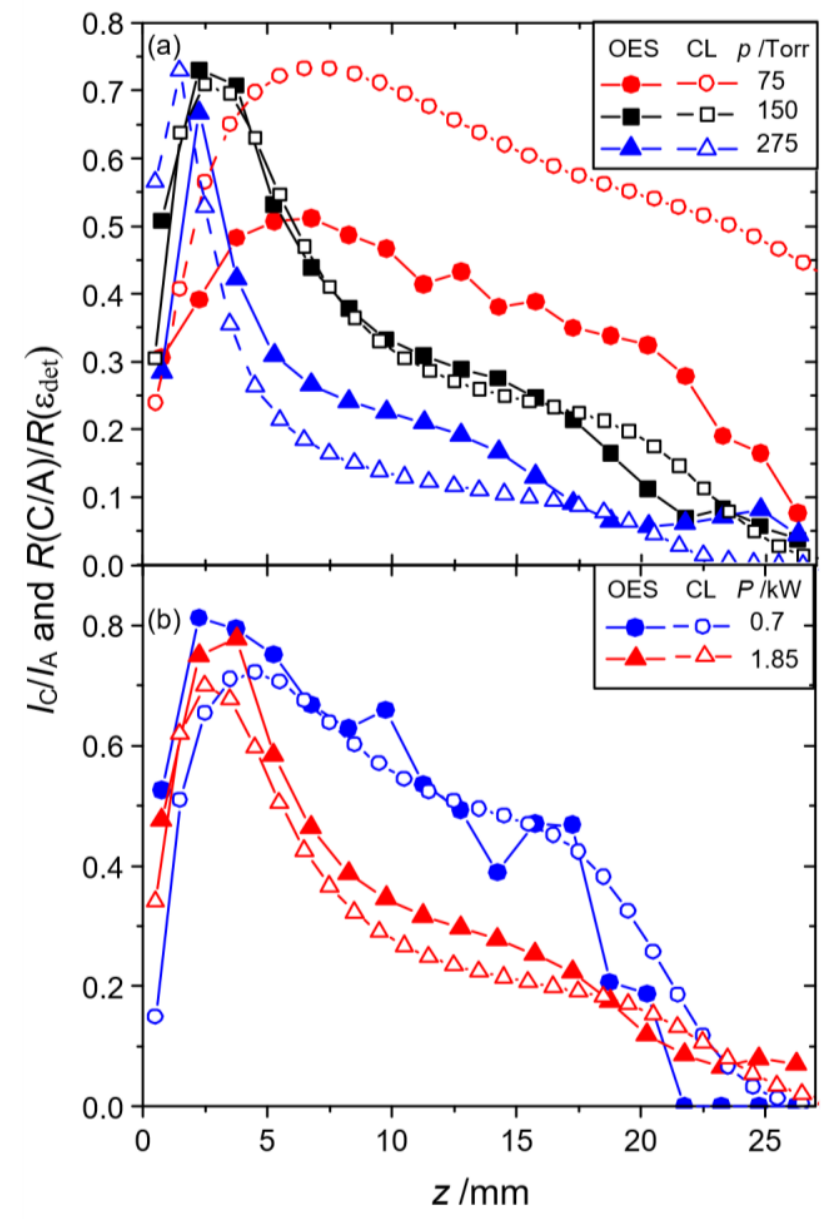




\section{Figure S5}

Calculated axial $(r=0, z)$ profiles of the $\mathrm{CH}(\mathrm{C})$ production (EIE, reaction (10) and CL, reaction (14)) and loss (radiative decay (11) and quenching via collision with $\mathrm{H}_{2}$ and with $\mathrm{H}$ atoms (reactions (12) and (13)) rates for $p=$ (a) 75, (b) 150 and (c) 275 Torr with all other parameters maintained at base conditions.

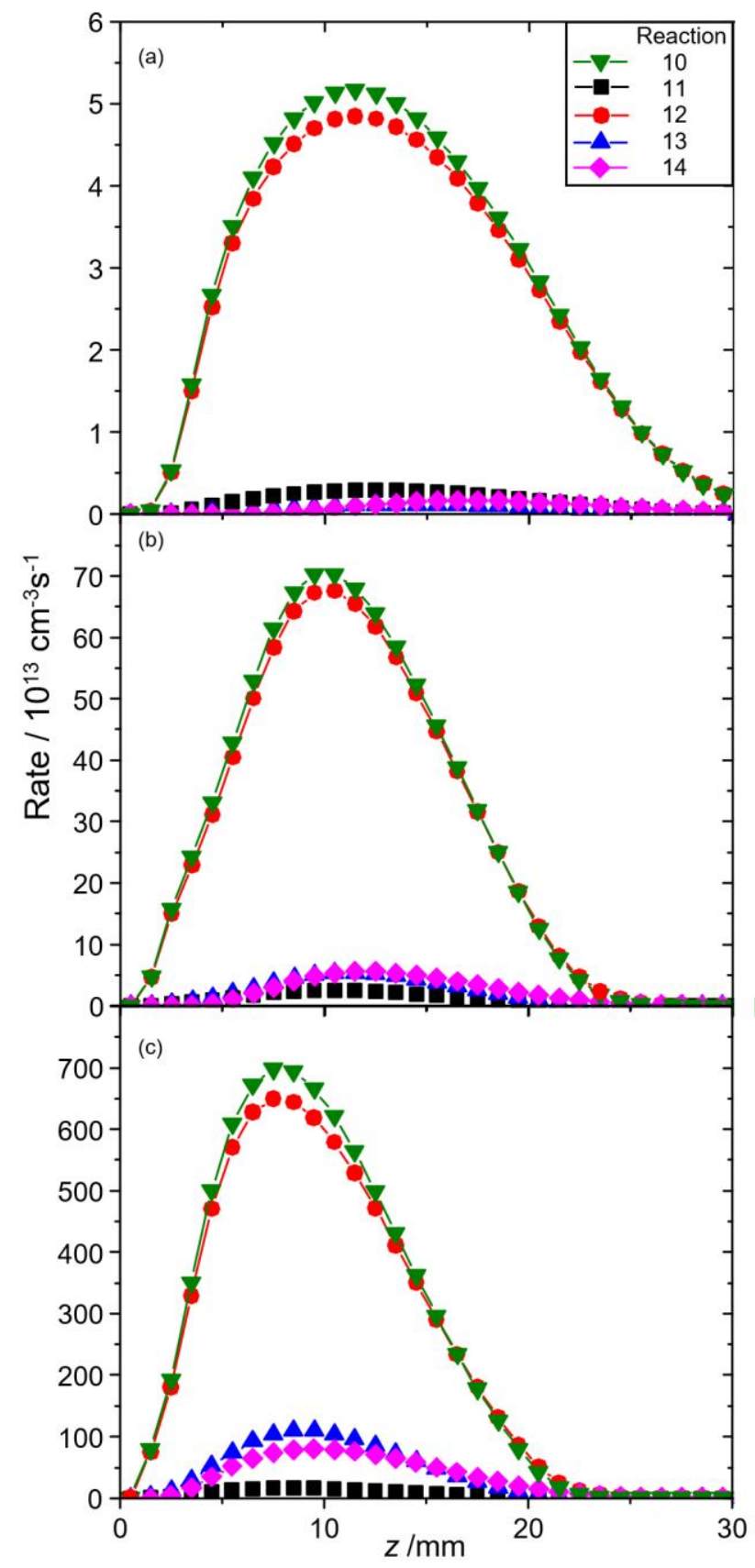




\section{Quenching Rate Coefficients for $\mathrm{CH}(\mathrm{A}), \mathrm{CH}(\mathrm{B})$ and $\mathrm{CH}(\mathrm{C})$}

The available quenching rate data for the three $\mathrm{CH}$ states of current interest are limited. Table S1 lists quenching rate coefficients, $k_{\mathrm{Q}, \mathrm{A}}$ measured and/or estimated for $\mathrm{CH}(\mathrm{A})$ with $\mathrm{H}_{2}, \mathrm{H}_{\text {and }} \mathrm{C}_{2} \mathrm{H}_{4}$ at low $\left(T_{\text {gas }}\right.$ $=300 \mathrm{~K})$ and high $\left(T_{\text {gas }}=3000 \mathrm{~K}\right) \cdot{ }^{43-48}$ Heinrich et al.${ }^{43}$ and Chen et al.${ }^{46}$ provide experimentally-derived rate coefficient expressions in Arrhenius form for quenching by $\mathrm{H}_{2}\left(300 \mathrm{~K} \leq T_{\text {gas }} \leq 950 \mathrm{~K}\right)$ and $\mathrm{C}_{2} \mathrm{H}_{4}$ $\left(297 \mathrm{~K} \leq T_{\text {gas }} \leq 653 \mathrm{~K}\right)$. Tamura et al. ${ }^{48}$ report calculated values for quenching by $\mathrm{H}$ and $\mathrm{H}_{2}$ over the range $240 \mathrm{~K} \leq T_{\text {gas }} \leq 1300 \mathrm{~K}$. The expressions of Heinrich et al. ${ }^{43}$ and Chen et al. ${ }^{46}$ satisfactorily reproduce the $k_{\mathrm{Q}}\left(T_{\text {gas }}=300 \mathrm{~K}\right)$ values for $\mathrm{Q}=\mathrm{C}_{2} \mathrm{H}_{4}$ and $\mathrm{H}_{2}$ reported by Cooper et al. ${ }^{47}$ and for $\mathrm{Q}=\mathrm{H}_{2}$, $\mathrm{C}_{2} \mathrm{H}_{2}$ and $\mathrm{C}_{2} \mathrm{H}_{4}$ reported by Nokes et al. ${ }^{44}$ Extrapolating the Arrhenius expressions for $\mathrm{CH}(\mathrm{A})$ state quenching provided by Heinrich et al. and Chen et al. to $T_{\mathrm{gas}}=3000 \mathrm{~K}$ yields comparable $k_{\mathrm{Q}, \mathrm{A}}$ values for $\mathrm{C}_{2} \mathrm{H}_{4}$ and $\mathrm{H}_{2} ; 4.52 \times 10^{-10}$ and $5.75 \times 10^{-10} \mathrm{~cm}^{3} \mathrm{~s}^{-1}$, respectively. Tamura et al. overestimate the measured $k_{\mathrm{Q}, \mathrm{A}}$ values with $\mathrm{H}_{2}$ at $T_{\text {gas }}=300 \mathrm{~K}$, but their calculated rate coefficient for $\mathrm{Q}=\mathrm{H}_{2}$ at $T_{\text {gas }}=$ $3000 \mathrm{~K}$ is of the same magnitude to this extrapolated value. Finally we note that the very similar $k_{\mathrm{Q}, \mathrm{A}}$ values have been found for quenching by $\mathrm{C}_{2} \mathrm{H}_{4}$ and $\mathrm{C}_{2} \mathrm{H}_{2}$ at $T_{\text {gas }} \sim 300 \mathrm{~K}^{44}$ The present modelling (summarized in Table 1) assumes similar high temperature $k_{\mathrm{Q}, \mathrm{A}}$ values for quenching by $\mathrm{H}_{2} \mathrm{H}_{2}$ and $\mathrm{C}_{2} \mathrm{H}_{2}$ which, given the relative abundances of these different species in the hot plasma region, implies that collisions with $\mathrm{H}_{2}$ are likely to dominate the quenching of $\mathrm{CH}(\mathrm{A})$ species and that the quenching rate will greatly exceed the radiative decay rate.

Even less is known about the temperature dependent quenching of the $\mathrm{CH}(\mathrm{B})$ and $\mathrm{CH}(\mathrm{C})$ states. Cooper et al. ${ }^{47}$ reported rate coefficients for $\mathrm{CH}(\mathrm{B})$ and $\mathrm{CH}(\mathrm{C})$ quenching with $\mathrm{C}_{2} \mathrm{H}_{4}$ and $\mathrm{H}_{2}$ at $T_{\text {gas }}=297 \mathrm{~K}$ similar to the values for $\mathrm{CH}(\mathrm{A})$. In the absence of other data, the present modelling assumes similar $k_{\mathrm{Q}, \mathrm{C}}\left(T_{\mathrm{gas}}\right)$ and $k_{\mathrm{Q}, \mathrm{A}}\left(T_{\mathrm{gas}}\right)$ values for $\mathrm{Q}=\mathrm{H}_{2}$ (Table 1$)$ and that the rate of $\mathrm{CH}(\mathrm{C})$ quenching by any other collision partner is (relatively) much smaller. We also note reports of collision-induced coupling between the $\mathrm{B}$ and $\mathrm{A}$ states of $\mathrm{CH},{ }^{47}$ which might contribute to the near-constant $R(\mathrm{~B} / \mathrm{A})$ value observed at higher $z$ values in the present work for $p \geq 150$ Torr (Figures 2(d) and 3(b)). Alternatively, however, we recognise that this may simply indicate that the $\mathrm{CH}(\mathrm{A})$ and $\mathrm{CH}(\mathrm{B})$ states have broadly similar production (EIE and via chemiluminescent reaction) and loss rates, all of which are likely to exceed the rates of collisional coupling rates. This uncertainty, and the larger energy separation between the $\mathrm{C}$ and A states, encourages us to focus modelling efforts on the $R(\mathrm{C} / \mathrm{A})$ ratio. 


\section{Table S1}

Summary of Measured/Calculated Rate Coefficients for Quenching of $\mathrm{CH}(\mathrm{A})$ Species in Collision with $\mathrm{H}, \mathrm{H}_{2}$ and $\mathrm{C}_{2} \mathrm{H}_{x}(x=2,4)$ at Low $\left(T_{\text {gas }} \sim 300 \mathrm{~K}\right)$ and High $\left(T_{\text {gas }} \sim 3000 \mathrm{~K}\right)$ Gas Temperatures.

\begin{tabular}{|l|l|l|l|}
\hline \multicolumn{1}{|c|}{$\mathbf{Q}$} & $T_{\text {gas }} / \mathbf{K}$ & \multicolumn{2}{|c|}{$k_{\mathbf{Q}} / \mathbf{1 0}^{-10} \mathbf{c m}^{3} \mathbf{m o l e c u l e}^{-1} \mathbf{s}^{-\mathbf{1}}$ ref. } \\
\hline & & \multicolumn{1}{|c|}{ experimental } & \multicolumn{1}{c|}{ calculated } \\
\hline $\mathrm{H}$ & 300 & - & $0.339^{48}$ \\
\hline $\mathrm{H}$ & 3000 & - & $2.653^{48}$ \\
\hline $\mathrm{H}_{2}$ & 300 & $0.123 \pm 0.006^{47}$ & $0.104^{43}$ \\
& & $0.090 \pm 0.08^{44}$ & $0.247^{48}$ \\
\hline $\mathrm{H}_{2}$ & 3000 & - & $5.753^{45}$ \\
& & & $1.938^{48}$ \\
\hline $\mathrm{C}_{2} \mathrm{H}_{x}$ & 300 & $1.81 \pm 0.20(\text { for } x=4)^{47}$ & 2.200 (for $x=4)^{46}$ \\
& & $1.9 \pm 0.1$ (for $x=2$ and 4) ${ }^{44}$ & 4.522 (for $x=4)^{46}$ \\
\hline $\mathrm{C}_{2} \mathrm{H}_{x}$ & 3000 & - & \\
\hline
\end{tabular}

References (numbered as in main paper)

${ }^{43}$ Heinrich, P.; Stuhl, F. Temperature Dependent Quenching of $\mathrm{CH}\left(\mathrm{A}^{2} \Delta\right), \mathrm{NH}\left(\mathrm{A}^{3} \Pi\right), \mathrm{NH}\left(\mathrm{c}^{1} \Pi\right)$, and PH(A $\left.{ }^{3} \Pi\right)$ by $\mathrm{H}_{2}$. Chem. Phys. 1995, 199, 297-304.

${ }^{44}$ Nokes, C.J.; Donovan, R.J. Time-Resolved Kinetic Studies of Electronically Excited CH Radicals II. Quenching Efficiencies for $\mathrm{CH}\left(\mathrm{A}^{2} \Delta\right)$. Chem. Phys. 1984, 90, 167-174.

${ }^{45}$ Garland, N.L.; Crosley, D.R. Collisional Quenching of $\mathrm{CH} \mathrm{A}^{2} \Delta, \mathrm{v}^{\prime}=0$ at 1300 K. Chem. Phys. Lett. 1987, 134, 189-194.

${ }^{46}$ Chen, C.; Wang, F.; Chen, Y.; Ma, X. Temperature Effect on Quenching of $\mathrm{CH}\left(\mathrm{A}^{2} \Delta\right)$. Chem. Phys. 1998, 230, 317-325.

${ }^{47}$ Cooper, J.L.; Whitehead, J.C. Collisional Removal Rates for Electronically Excited CH Radicals B ${ }^{2} \Sigma^{-}$ and $\mathrm{C}^{2} \Sigma^{+}$. J. Chem. Soc. Faraday Trans. 1992, 88, 2323-2327.

${ }^{48}$ Tamura, M.; Berg, P.A.; Harrington, J.E.; Luque, J.; Jeffries, J.B.; Smith, G.P.; Crosley, D.R. Collisional Quenching of $\mathrm{CH}(\mathrm{A}), \mathrm{OH}(\mathrm{A})$, and $\mathrm{NO}(\mathrm{A})$ in Low Pressure Hydrocarbon Flames. Combust. Flame 1998, 114, 502-514. 


\section{Uncertainties Regarding the Kinetics of the ${ }^{1} \mathrm{CH}_{2}+\mathrm{H} \rightarrow \mathrm{CH}(\mathrm{X})+\mathrm{H}_{2}$ Reaction at High Temperatures}

The values of the rate coefficients for the CL reactions (i.e. $k_{9}, k_{9 \mathrm{a}}$ and $k_{9 \mathrm{~b}}$ in Table 1 of the paper) will be sensitive to uncertainties in the $\mathrm{CH}(\mathrm{X})$ concentrations $([\mathrm{CH}(\mathrm{X})](r, z))$ at high gas temperatures $\left(T_{\text {gas }}\right.$ $\sim 3000 \mathrm{~K})$. The 2-D model shows that $[\mathrm{CH}(\mathrm{X})]$ is determined mainly by a local balance of the fast, direct and reverse reactions (17) and (-17):

$$
\begin{aligned}
& { }^{3} \mathrm{CH}_{2}+\mathrm{H} \rightarrow \mathrm{CH}(\mathrm{X})+\mathrm{H}_{2} \\
& \mathrm{CH}(\mathrm{X})+\mathrm{H}_{2} \rightarrow{ }^{3} \mathrm{CH}_{2}+\mathrm{H}
\end{aligned}
$$

We are not aware of any direct measurements of the rate coefficients $k_{17}$ and $k_{-17}$ at high temperatures. The rate coefficients measured at lower temperatures $\left(T_{\mathrm{gas}}<1000 \mathrm{~K}\right)$ and calculated by various theoretical methods ${ }^{1-3}$ could be used to determine possible ranges of $k_{17}$ and $k_{-17}$ at the high temperatures of current interest: e.g. $k_{17} \sim(2.5-3) \times 10^{-10} \mathrm{~cm}^{3} \mathrm{~s}^{-1}$ and $k_{-17} \sim(1.5-4) \times 10^{-10} \mathrm{~cm}^{3} \mathrm{~s}^{-1}$ at $T_{\text {gas }} \sim 3000 \pm 300 \mathrm{~K}$. These fast reactions are highly balanced under the prevailing plasma conditions and $[\mathrm{CH}(\mathrm{X})]$ is thus proportional to the ratio $k_{17} / k_{-17}$. The thermochemical data within the GRI Mechanism $3.0^{4}$ used in the current modelling provides the ratio $k_{17} / k_{-17} \sim 2.5$ at $T_{\text {gas }} \sim 3000 \mathrm{~K}$, which leads to higher predicted $\{\mathrm{CH}(\mathrm{X})\}$ column densities at base pressures and above (i.e. at $p \geq 150$ Torr) than measured in our previous cavity ring down absorption studies. ${ }^{5} 2$-D model calculations with a lower $k_{17} / k_{-17}$ ratio $(e . g$. $k_{17} / k_{-17} \sim 1$ at $\left.T_{\text {gas }} \sim 3000 \mathrm{~K}\right)$ afford better agreement between the calculated and measured $\{\mathrm{CH}(\mathrm{X})\}$ values and allow preservation of all the results and trends for $\mathrm{CH}^{*}$ (including the $I(\mathrm{C}) / I(\mathrm{~A})$ ) profiles) if the rate coefficients of the CL reactions (i.e. $k_{9}, k_{9 \mathrm{a}}$ and $k_{9 \mathrm{~b}}$ ) are reduced by a similar factor of 2.5. We also note that lower $k_{17} / k_{-17}$ ratios under the conditions prevailing in the plasma core could also be induced if the exothermicity of the fast reaction $(17)^{2}$ results in a non-thermal (i.e. over-equilibrium) distribution of $\mathrm{CH}(\mathrm{X}, v, J)$ product rovibrational states and thus a local enhancement of $k_{-17}$. A similar over-equilibrium product internal energy disposal has been proposed previously ${ }^{6}$ for the fast $\mathrm{CN}+\mathrm{H}_{2}$ $\leftrightarrow \mathrm{HCN}+\mathrm{H}$ reaction in MW activated $\mathrm{CH}_{4} / \mathrm{N}_{2} / \mathrm{H}_{2}$ plasmas .

\section{References}

${ }^{1}$ S. Zabarnick, S.; Fleming, J.W.; Lin, M.C. Kinetic Study of the Reaction $\mathrm{CH}\left(\mathrm{X}^{2} \Pi\right)+\mathrm{H}_{2} \rightarrow \mathrm{CH}_{2}\left(\mathrm{X}^{3} \mathrm{~B}_{1}\right)$

+ H in the Temperature Range 372 to 675 K. J. Chem. Phys. 1986, 85, 4373-4376.

${ }^{2}$ Garcia, E.; Jambrina, P.G.; Laganà, A. Kinetics of the $\mathrm{H}+\mathrm{CH}_{2} \rightarrow \mathrm{CH}+\mathrm{H}_{2}$ Reaction at Low Temperature. J. Phys. Chem. A 2019, in press. DOI: 10.1021/acs.jpca.9b06212.

${ }^{3}$ González, M.; Saracibar, A.; Garcia, E. Capture and Dissociation in the Complex-Forming $\mathrm{CH}+\mathrm{H}_{2}$ $\rightarrow \mathrm{CH}_{2}+\mathrm{H}, \mathrm{CH}+\mathrm{H}_{2}$ Reactions. Phys. Chem. Chem. Phys., 2011, 13, 3421-3428. 
${ }^{4}$ Smith, G.P.; Golden, D.M.; Frenklach, M.; Moriarty, N.W.; Eiteneer, B.; Goldenburg, M.; Bowman, C.T.; Hanson, R.K.; Song, S.; Gardiner, W.C., Jr.; Lissianski, V.V.; Qin, Z.W. GRI-Mech 3.0. Available at http://www.me.berkeley.edu/gri_mech/(accessed 2016)

${ }^{5}$ Ma, J.; Richley, J.C.; Ashfold, M.N.R.; Mankelevich, Yu.A. Probing the Plasma Chemistry in a Microwave Reactor used for Diamond Chemical Vapor Deposition by Cavity Ring Down Spectroscopy. J. Appl. Phys. 2008, 104, 103305.

${ }^{6}$ Truscott, B.S.; Kelly, M.W.; Potter, K.J.; Ashfold, M.N.R.; Mankelevich, Yu.A. Microwave PlasmaActivated Chemical Vapor Deposition of Nitrogen-Doped Diamond. II: $\mathrm{CH}_{4} / \mathrm{N}_{2} / \mathrm{H}_{2}$ Plasmas. J. Phys. Chem. A 2016, 120, 8537-8549. 